\title{
Interaction between smoking and diabetes in relation to subsequent risk of cardiovascular events
}

\author{
Yang Yang ${ }^{1 \dagger}$, Nianchun Peng ${ }^{1 \dagger}$, Gang Chen ${ }^{2}$, Qin Wan ${ }^{3}$, Li Yan $^{4}$, Guixia Wang ${ }^{5}$, Yingfen Qin ${ }^{6}$, Zuojie Luo ${ }^{6}$, \\ Xulei Tang ${ }^{7}$, Yanan Huo ${ }^{8}$, Ruying Hu ${ }^{9}$, Zhen Ye ${ }^{9}$, Guijun Qin ${ }^{10}$, Zhengnan Gao ${ }^{11}$, Qing Su ${ }^{12}$, Yiming Mu ${ }^{13}$, \\ Jiajun Zhao ${ }^{14}$, Lulu Chen ${ }^{15}$, Tianshu Zeng ${ }^{15}$, Xuefeng Yu ${ }^{16}$, Qiang Li ${ }^{17}$, Feixia Shen ${ }^{18}$, Li Chen ${ }^{19}$, Yinfei Zhang ${ }^{20}$,

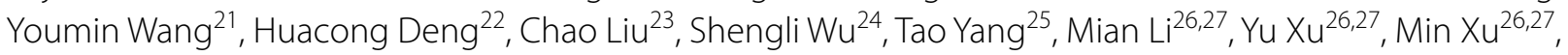 \\ Zhiyun Zhao ${ }^{26,27}$, Tiange Wang 26,27, Jieli Lu ${ }^{26,27}$, Yufang Bi ${ }^{26,27}$, Weiqing Wang ${ }^{26,27}$, Guang Ning ${ }^{26,27}$, \\ Qiao Zhang ${ }^{1,28^{*}}$ and Lixin Shi ${ }^{1,28^{*}}$ (1)
}

\begin{abstract}
Background: Whether smoking modifies the associations of diabetes and risk factor management with subsequent risk of cardiovascular disease (CVD), and whether the smoking related CVD risk differs among people with and without diabetes are unclear. This study aimed to examine the associations and interactions of smoking, diabetes, and risk factor management in relation to incident CVD.
\end{abstract}

Methods: This nationwide, population-based, prospective cohort study of 20 communities from various geographic regions recruited adults aged 40 years or older during 2011-2012. The follow-up survey was conducted between 2014 and 2016. This study included 126,181 participants who were free from CVD at baseline.

Results: Study participants included 19,397 current smokers (15.4\%), 6,049 former smokers (4.8\%), and 100,735 never smokers (79.8\%). Mean (SD) age ranged from 55.8 (8.6) years to 60.7 (9.1) years. Compared with never smokers, heavy smokers exhibited a greater risk of CVD events among participants with diabetes (multivariable-adjusted hazard ratio $[\mathrm{HR}], 1.45 ; 95 \% \mathrm{Cl}, 1.17-1.78)$ than among participants without diabetes (HR, 1.20; 95\% Cl, 1.01-1.42; P for interaction $=0.006$ ). Compared with participants without diabetes, participants with diabetes who were never smokers and had 5 or more controlled risk factors showed no significantly excess CVD risk (HR, 0.93; 95\% Cl, 0.71-1.22), but the cardiovascular benefits from risk factor management were counteracted among participants with diabetes who were current smokers ( $\mathrm{HR}, 1.28 ; 95 \% \mathrm{Cl}, 0.77-2.14)$ or former smokers ( $\mathrm{HR}, 1.22 ; 95 \% \mathrm{Cl}, 0.66-2.28)$.

Conclusions: Smoking and diabetes interacted with each other in relation to increased risk of CVD events, and the beneficial effect of risk factor management on CVD risk among participants with diabetes was attenuated by current or former smoking.

Keywords: Diabetes, Risk of cardiovascular disease, Smoking, Risk factor management

\footnotetext{
*Correspondence: endocrine_zq@126.com; slx1962@medmail.com.cn †Yang Yang and Nianchun Peng contributed equally as first authors ${ }^{1}$ Department of Endocrinology and Metabolism, Affiliated Hospital of Guizhou Medical University, Guizhou Medical University, Guiyang, China

Full list of author information is available at the end of the article
}

\section{Introduction}

Cigarette smoking is the leading preventable cause of morbidity and mortality worldwide, responsible for $11.5 \%$ (equivalent to 6.4 million) of global deaths annually $[1,2]$. In China, smoking has been ranked as the original author(s) and the source, provide a link to the Creative Commons licence, and indicate if changes were made. The images or other third party material in this article are included in the article's Creative Commons licence, unless indicated otherwise in a credit line to the material. If material is not included in the article's Creative Commons licence and your intended use is not permitted by statutory regulation or exceeds the permitted use, you will need to obtain permission directly from the copyright holder. To view a copy of this licence, visit http://creativecommons.org/licenses/by/4.0/. The Creative Commons Public Domain Dedication waiver (http://creativeco mmons.org/publicdomain/zero/1.0/) applies to the data made available in this article, unless otherwise stated in a credit line to the data. 
most important lifestyle risk factor contributing to deaths and disability-adjusted life-years [3]. Smoking substantially increases the risk of cardiovascular disease (CVD) in both the general population and patients with type 2 diabetes [4-6]. Compared with people without diabetes, patients with diabetes have a twofold additional hazard of CVD, occurring earlier and with greater severity [79]; meanwhile CVD remains the most common cause of mortality among patients with diabetes [10]. Therefore, interventions to prevent or quit smoking, together with cardiovascular risk factor management such as glycemic control and the management of blood pressure and cholesterol, are key recommendations for the prevention of CVD in diabetes $[11,12]$.

Smoking prevention and cessation interventions compare favorably with the management of other cardiovascular risk factors, in terms of both health improvements and cost savings [13]. However, a considerable proportion of people are likely to continue smoking even after a diagnosis of diabetes [14], and the successful rate of smoking cessation interventions for smokers with diabetes is not ideal [15]. Evaluating the interplay between cigarette smoking and diabetes status in relation to CVD risk is of the essence for prioritizing precise clinical and public health strategies to reduce the burden of CVD among patients with diabetes. Thus far, whether current smoking or smoking cessation modifies the associations of diabetes and risk factor management with the incidence of CVD, and whether the smoking-related CVD risk differs among people with and without diabetes are still unknown.

To fill this knowledge gap, we investigated the bidirectional interactions of active smoking and smoking cessation with diabetes status on subsequent risk of CVD events, and examined the association of cardiovascular risk factor management in diabetes with the risk of CVD across smoking status categories in a nationwide prospective cohort study.

\section{Methods}

\section{Study participants}

The China Cardiometabolic Disease and Cancer Cohort (4C) Study is a multicenter, population-based, prospective cohort study $[16,17]$. The baseline survey was conducted between 2011 and 2012, and 19,3846 men and women aged 40 years or older were recruited from local resident registration systems of 20 communities from various geographic regions in China to represent the general population. The follow-up survey was conducted between 2014 and 2016; all participants were invited to attend an in-person visit, and 170,240 participants $(87.8 \%)$ were followed up. The analysis included
126,181 participants who had complete baseline data on cigarette smoking, diabetes status, and covariates; were free from CVD at baseline; and had complete ascertainment of CVD events at the follow-up visit. This study was approved by the Medical Ethics Committee of Ruijin Hospital, Shanghai Jiao Tong University. All study participants provided written informed consent.

\section{Data collection}

Data collection was performed in local community clinics by trained study personnel according to standard protocols. Questionnaires comprising information on demographic characteristics, dietary and lifestyle factors, family history, and medical history were administered by trained interviewers. Education attainment was classified as less than high school ( $<9$ years) and high school or further education ( $\geq 9$ years). A food frequency questionnaire was used to collect habitual dietary intake by asking the consumption frequency and portion size of typical food items during the previous 12 months. International Physical Activity Questionnaire was used to assess physical activity [18], and Metabolic equivalent (MET) was calculated to evaluate average weekly energy expenditure [19]. Physical activity was classified as active ( $\geq 600$ MET$\mathrm{min} /$ week), insufficiently active ( $>0$ to $<600$ MET-min/ week), and inactive (0 MET-min/week). Average alcohol consumption was calculated by multiplying amount of alcohol consumed per drinking day by frequency.

Height and body weight were measured according to a standard protocol, and body mass index (BMI) was calculated as body weight in kilograms divided by the square of height in meters.

Three measurements of systolic blood pressure (SBP) and diastolic blood pressure (DBP) were obtained by using an automated electronic device (OMRON Model HEM-752 FUZZY, Dalian, China) in a seated position after at least a 5-min quiet rest, and the 3 readings were averaged for analysis. Hypertension was defined as $\mathrm{SBP} \geq 140 \mathrm{mmHg}$, or $\mathrm{DBP} \geq 90 \mathrm{mmHg}$, or taking antihypertensive medication.

All participants underwent a 2-h, 75-g oral glucose tolerance test (OGTT) after an overnight fast of at least $10 \mathrm{~h}$, and blood samples were collected at 0 and $2 \mathrm{~h}$ during the test. Fasting and 2-h plasma glucose concentrations were measured locally using a glucose oxidase or hexokinase method within $2 \mathrm{~h}$ after blood sample collection under a stringent quality control program. Finger capillary whole blood samples were collected by the Hemoglobin Capillary Collection System (Bio-Rad Laboratories, Hercules, CA, USA) and were shipped and stored at $2^{\circ} \mathrm{C}$ to $8^{\circ} \mathrm{C}$ until glycated hemoglobin $\mathrm{A} 1 \mathrm{C}$ (HbA1c) was measured within 4 weeks after collection 
by high-performance liquid chromatography using the VARIANT II Hemoglobin Testing System (Bio-Rad Laboratories) at the central laboratory in the Shanghai Institute of Endocrine and Metabolic Diseases, which was certificated by the National Glycohemoglobin Standardization Program and the College of American Pathologists Laboratory Accreditation Program.

Serum low-density lipoprotein (LDL) cholesterol, high-density lipoprotein (HDL) cholesterol, triglycerides, total cholesterol, and creatinine were measured at the central laboratory using an auto-analyzer (ARCHITECT ci16200, Abbott Laboratories, Chicago, IL, USA). Dyslipidemia was defined as $\mathrm{LDL} \geq 160 \mathrm{mg} / \mathrm{dL}$ $(4.14 \mathrm{mmol} / \mathrm{L})$, or $\mathrm{HDL}<40 \mathrm{mg} / \mathrm{dL}(1.04 \mathrm{mmol} / \mathrm{L})$, or triglycerides $\geq 200 \mathrm{mg} / \mathrm{dL}(2.26 \mathrm{mmol} / \mathrm{L})$, or total cholesterol $\geq 240 \mathrm{mg} / \mathrm{dL}(6.22 \mathrm{mmol} / \mathrm{L})$, or taking lipid-lowering medications [20].

Estimated glomerular filtration rate (eGFR) was calculated using the Chronic Kidney Disease Epidemiology Collaboration equation [21]. Chronic kidney disease (CKD) was defined as eGFR $<60 \mathrm{~mL} / \mathrm{min} / 1.73 \mathrm{~m} \mathrm{[2]}$.

\section{Assessment of cigarette smoking, diabetes, and risk factor management}

Information on cigarette smoking was collected by a standard questionnaire. Current smokers were defined as participants who reported smoking cigarettes every day or almost every day, with at least 7 cigarettes per week for at least 6 months [2]. Intensity of current smoking was classified into light $(<10$ cigarettes per day), moderate $(10-<20$ cigarettes per day), and heavy ( $\geq 20$ cigarettes per day) levels by number of cigarettes smoked [22]. Former smokers were defined as participants who reported not currently smoke cigarettes but had smoked at least 7 cigarettes per week for at least 6 months in a lifetime [2]. Former smokers were classified into short-term quitters (quit for $<4$ years), medium-term quitters (quit for $4-<8$ years), and long-term quitters (quit for $\geq 8$ years) by years since smoking cessation. Never smokers were defined as participants who reported never smoked or had not smoked cigarettes regularly $(<100$ cigarettes in a lifetime) [2]. Passive smoking was defined as exposure to 1 or more smokers during childhood or adulthood.

According to the American Diabetes Association 2010 criteria, diabetes was defined as: fasting plasma glucose $\geq 126 \mathrm{mg} / \mathrm{dL}(7.0 \mathrm{mmol} / \mathrm{L})$, or OGTT 2-h plasma glucose $\geq 200 \mathrm{mg} / \mathrm{dL}$ ( $11.1 \mathrm{mmol} / \mathrm{L})$, or $\mathrm{HbA} 1 \mathrm{c} \geq 6.5 \%$, or a self-reported previous diagnosis of diabetes by health care professionals [23].

For participants with diabetes, we considered optimal management of 6 cardiovascular risk factors in accordance with previous studies: (1) fruits and vegetables intake $\geq 4.5 \mathrm{cup} /$ day [24]; (2) physical activity $\geq 600$ MET-min/week [24, 25]; (3) HbA1c <6.5\% [16, 26]; (4) $\mathrm{SBP}<130 \mathrm{mmHg}$ and $\mathrm{DBP}<80 \mathrm{mmHg}[27,28]$; (5) LDL cholesterol < $100 \mathrm{mg} / \mathrm{dL}$ [29]; (6) without CKD [29].

\section{Ascertainment of cardiovascular events}

The outcome was the composite of incident fatal or nonfatal CVD events, including cardiovascular death, myocardial infarction, stroke, and hospitalized or treated heart failure. The detailed definitions of CVD events have been described previously [16]. Deaths and clinical outcomes were collected from local vital registries of the National Disease Surveillance Point System and National Health Insurance System. Two members of the outcome adjudication committee independently verified each clinical event and assigned potential causes of death, and discrepancies were adjudicated by discussions involving other members of the committee. The members of the outcome adjudication committee were unaware of the baseline clinical characteristics of each participant.

\section{Statistical analysis}

Baseline characteristics of participants according to smoking status were summarized as means with standard deviations (SDs) for continuous variables and numbers with percentages for categorical variables. In the timeto-event analysis, participants were censored at the date of CVD diagnosis, death, or the end of follow-up, whichever occurred first. Person-time was calculated from the enrollment date to the censoring date for each participant. All participants had complete data of cigarette smoking, diabetes status, and covariates; missing data for risk factor variables were deleted from the analyses.

Cox proportional hazards models were used to calculate hazard ratios (HRs) and 95\% confidence intervals (CIs) for CVD events associated with current smoking and smoking cessation among participants with and without diabetes, with adjustment for traditional CVD risk factors as well as baseline BMI, change in BMI during the follow-up period, and passive smoking. Associations of diabetes as well as elevated fasting glucose, elevated OGTT-2 h glucose, and elevated HbA1c with CVD events among current smokers, former smokers, and never smokers were also established. Multiplicative interactions between smoking and diabetes on CVD events were tested by including the product term (e.g., smoking status category $\times$ diabetes category) as well as smoking status and diabetes status in the models. We performed additional analyses to assess the associations and interactions between smoking and diabetes on nonfatal CVD events and CVD mortality. The numbers of 
well-managed risk factors were summed for each participant to represent an overall management of all 6 risk factors. Associations of individual and overall cardiovascular risk factor management with CVD events among participants with diabetes according to smoking status, as compared with participants without diabetes were analyzed.

Statistical significance was assessed using a two-sided $P$ value of $<0.05$. Statistical analyses used SAS software, version 9.4 (SAS Institute Inc).

\section{Results}

Baseline characteristics of participants according to smoking status are shown in Table 1. Of the 126,181 participants, there were 19,397 current smokers (15.4\%), 6,049 former smokers (4.8\%), and 100,735 never smokers (79.8\%). Compared with never smokers, current smokers or former smokers had higher proportions of men, were more likely to be exposed to passive smoking in childhood, and had lower proportions of family history of CVD. Current smokers consumed fewer fruits and vegetables, were less physically active, and had higher levels of alcohol consumption than former smokers or never smokers. Former smokers had poorer glucose profiles and higher blood pressures than current smokers or never smokers.

During 455,726 person-years (median, 3.2 years; interquartile range, 3.0-4.7 years) of follow-up, we documented 3,422 CVD events: 679 participants died from cardiovascular cause, 514 had myocardial infarction, 2,055 had stroke, and 251 had heart failure; participants may have experienced more than $1 \mathrm{CVD}$ event. Compared with never smokers, current smokers had significantly higher hazard of CVD events among participants

Table 1 Baseline characteristics of participants according to smoking status

\begin{tabular}{|c|c|c|c|c|c|}
\hline \multirow[t]{2}{*}{ Characteristic } & \multirow[t]{2}{*}{ Current smokers } & \multicolumn{3}{|l|}{ Former smokers } & \multirow[t]{2}{*}{ Never smokers } \\
\hline & & Quit for $<4$ years & Quit for $4-<8$ years & Quit for $\geq 8$ years & \\
\hline Number of participants & 19,397 & 2405 & 848 & 2796 & 100,735 \\
\hline Age, year & $55.8(8.6)$ & $58.2(8.9)$ & $59.4(8.5)$ & $60.7(9.1)$ & $56.4(9.0)$ \\
\hline Men, n (\%) & $18,230(94.0)$ & $2247(93.4)$ & $800(94.3)$ & $2684(96.0)$ & $19,609(19.5)$ \\
\hline High school or further education, n (\%) & $6761(34.9)$ & $953(39.6)$ & $372(43.9)$ & $1237(44.2)$ & $36,787(36.5)$ \\
\hline Family history of diabetes, n (\%) & $2310(11.9)$ & $305(12.7)$ & $104(12.3)$ & $370(13.2)$ & $13,292(13.2)$ \\
\hline Family history of CVD, n (\%) & $2575(13.3)$ & $332(13.8)$ & $137(16.2)$ & $416(14.9)$ & $17,491(17.4)$ \\
\hline $\mathrm{BMI}, \mathrm{kg} / \mathrm{m}^{2}$ & $24.4(3.5)$ & $25.0(3.5)$ & $25.3(3.5)$ & $25.3(3.6)$ & $24.6(3.6)$ \\
\hline Passive smoking exposure in childhood, n (\%) & $11,708(60.4)$ & $1450(60.3)$ & $491(57.9)$ & $1642(58.7)$ & $45,019(44.7)$ \\
\hline Passive smoking exposure in adulthood, n (\%) & $7536(38.9)$ & $770(32.0)$ & $249(29.4)$ & $886(31.7)$ & $36,188(35.9)$ \\
\hline Fruits and vegetables intake, cup/day & $3.9(3.6)$ & $4.2(4.0)$ & $4.7(6.5)$ & $5.2(26.9)$ & $4.2(5.6)$ \\
\hline \multicolumn{6}{|l|}{ Physical activity, n (\%) } \\
\hline Active & $11,474(59.2)$ & 1609 (66.9) & $607(71.6)$ & $2078(74.3)$ & $65,414(64.9)$ \\
\hline Insufficiently active & $7425(38.3)$ & $734(30.5)$ & $224(26.4)$ & $671(24.0)$ & $32,590(32.4)$ \\
\hline Inactive & $498(2.6)$ & $62(2.6)$ & $17(2.0)$ & $47(1.7)$ & $2731(2.7)$ \\
\hline Alcohol consumption, g/day & $24.8(45.1)$ & $21.3(44.6)$ & $20.1(40.7)$ & $18.3(36.2)$ & $2.3(13.7)$ \\
\hline \multicolumn{6}{|l|}{ Glucose profile } \\
\hline Fasting glucose, mg/dL & $108.6(32.4)$ & $112.0(33.2)$ & $114.4(33.0)$ & $113.3(34.2)$ & $106.6(28.6)$ \\
\hline OGTT-2 h glucose, mg/dL & $143.9(73.9)$ & $154.7(76.5)$ & $164.5(77.3)$ & $160.0(78.6)$ & $147.8(66.8)$ \\
\hline $\mathrm{HbA} 1 \mathrm{c}, \%$ & $6.0(1.1)$ & $6.1(1.2)$ & $6.2(1.2)$ & $6.2(1.1)$ & $6.0(1.0)$ \\
\hline \multicolumn{6}{|l|}{ Blood pressure } \\
\hline $\mathrm{SBP}, \mathrm{mm} \mathrm{Hg}$ & $132.9(20.0)$ & $136.3(20.3)$ & $136.9(18.7)$ & $136.7(20.0)$ & $132.6(20.9)$ \\
\hline $\mathrm{DBP}, \mathrm{mm} \mathrm{Hg}$ & $79.8(11.5)$ & $80.7(11.3)$ & $81.6(11.2)$ & $80.8(11.2)$ & $78.0(11.0)$ \\
\hline \multicolumn{6}{|l|}{ Lipid profile } \\
\hline LDL cholesterol, mg/dL & $108.1(32.3)$ & $108.4(33.1)$ & $105.7(33.3)$ & $108.5(33.6)$ & $112.2(34.2)$ \\
\hline HDL cholesterol, mg/dL & $49.3(15.0)$ & $48.3(14.1)$ & $47.5(14.7)$ & $47.6(13.1)$ & $52.5(13.8)$ \\
\hline Triglycerides, mg/dL & $158.6(132.8)$ & $154.4(120.5)$ & $157.9(130.4)$ & $148.5(109.5)$ & $142.0(103.4)$ \\
\hline Total cholesterol, mg/dL & $187.3(42.2)$ & $186.4(44.0)$ & $182.6(43.4)$ & $185.0(44.1)$ & $193.5(44.2)$ \\
\hline $\mathrm{eGFR}, \mathrm{mL} / \mathrm{min} / 1.73 \mathrm{~m}^{2}$ & $95.6(13.2)$ & $92.7(14.3)$ & $91.1(14.9)$ & $89.8(15.2)$ & $93.6(13.4)$ \\
\hline
\end{tabular}

Values are mean (SD) for continuous variables and number (proportion) for categorical variables. Overall, the numbers of missing values are 120 for fasting glucose, 683 for OGTT-2 h glucose, 179 for HbA1c, 666 for SBP, 673 for DBP, 276 for LDL cholesterol, 278 for HDL cholesterol, 380 for triglycerides, 259 for total cholesterol, and 297 for eGFR. Percentages may not sum to $100 \%$ due to rounding 
Table 2 Association of smoking with CVD events among participants with and without diabetes

\begin{tabular}{|c|c|c|c|c|c|c|c|}
\hline \multirow[t]{2}{*}{ Category } & \multirow{2}{*}{$\begin{array}{l}\text { No. of } \\
\text { participants }\end{array}$} & \multirow[t]{2}{*}{ Person-years } & \multirow[t]{2}{*}{ Cases } & \multicolumn{3}{|l|}{ HR $(95 \% \mathrm{Cl})$} & \multirow[t]{2}{*}{$P$ for interaction ${ }^{c}$} \\
\hline & & & & $\begin{array}{l}\text { Adjusted } \\
\text { for CVD risk } \\
\text { factors }^{\mathrm{a}}\end{array}$ & $\begin{array}{l}\text { Further adjusted for } \\
\text { baseline BMI, and BMI } \\
\text { change }\end{array}$ & $\begin{array}{l}\text { Further adjusted } \\
\text { for passive } \\
\text { smoking }^{b}\end{array}$ & \\
\hline Diabetes & & & & & & & 0.034 \\
\hline Never smokers & 22,764 & 81,515 & 943 & 1.00 [Ref.] & 1.00 [Ref.] & 1.00 [Ref.] & \\
\hline Former smokers & 1913 & 6889 & 112 & $1.15(0.92-1.43)$ & $1.15(0.92-1.43)$ & $1.15(0.93-1.43)$ & \\
\hline Current smokers & 4523 & 16,226 & 233 & $1.29(1.08-1.54)$ & $1.29(1.08-1.53)$ & $1.29(1.08-1.54)$ & \\
\hline \multicolumn{8}{|l|}{ No diabetes } \\
\hline Never smokers & 77,971 & 281,612 & 1604 & 1.00 [Ref.] & 1.00 [Ref.] & 1.00 [Ref.] & \\
\hline Former smokers & 4136 & 15,002 & 128 & $1.07(0.88-1.30)$ & $1.06(0.88-1.30)$ & $1.07(0.88-1.30)$ & \\
\hline Current smokers & 14,874 & 54,483 & 402 & $1.23(1.07-1.41)$ & $1.24(1.08-1.42)$ & $1.24(1.09-1.43)$ & \\
\hline
\end{tabular}

126,181 participants were included in the analysis

${ }^{a}$ Adjusted for age, sex, education attainment (less than high school, high school or further education), family history of diabetes (yes, no), family history of CVD (yes, no), fruits and vegetables intake ( $<4.5$ cup/day, $\geq 4.5$ cup/day), physical activity (active, insufficiently active, inactive), alcohol consumption, hypertension (yes, no), and dyslipidemia (yes, no)

${ }^{\mathrm{b}}$ Adjusted for CVD risk factors as listed above, as well as baseline BMI, BMI change during follow-up, and passive smoking exposure in childhood and adulthood ${ }^{\mathrm{C}}$ Interaction of diabetes with smoking status in relation to CVD events was adjusted for CVD risk factors as listed above, as well as baseline BMI, BMI change during follow-up, and passive smoking exposure in childhood and adulthood

with diabetes (HR, 1.29; 95\% CI, 1.08-1.54) than among participants without diabetes (HR, 1.24; 95\% CI, 1.09-1.43; P for interaction $=0.034$; Table 2). A significant interaction between current smoking intensity and diabetes on CVD events was also identified: the HRs for comparison of heavy smokers with never smokers were 1.45 (95\% CI, 1.17-1.78) among participants with diabetes and 1.20 (95\% CI, 1.01-1.42) among participants without diabetes ( $\mathrm{P}$ for interaction $=0.006$; Fig. $1 \mathrm{~A}$ ). A graded inverse association between years since smoking cessation and CVD events was observed: the HRs as compared with current smokers were 1.14 (95\% CI, $0.83-1.56)$ for short-term quitters and 0.78 (95\% CI, 0.57-1.06) for long-term quitters among participants with diabetes, and were 1.10 (95\% CI, 0.84-1.43) for short-term quitters and 0.63 (95\% CI, 0.46-0.85) for long-term quitters among participants without diabetes (P for interaction $=0.86$; Fig. 1B). We observed similar associations of current smoking and smoking cessation with fatal and non-fatal CVD events, separately (Additional file 1: Figures S1, S2).

Diabetes as well as elevated fasting glucose, elevated OGTT-2 h glucose, and elevated HbA1c were associated with increased hazards of CVD events, and these associations were more prominent among current smokers and former smokers than among never smokers (Table 3). The multivariable-adjusted HRs for CVD events associated with diabetes were 1.61 (95\% CI, 1.36-1.91) among current smokers, 1.70 (95\% CI, 1.31-2.22) among former smokers, and 1.37 (95\%
CI, 1.26-1.49) among never smokers ( $\mathrm{P}$ for interaction $=0.034)$. Significant interaction was also observed for elevated HbA1c (P for interaction $=0.011$ ), whereas no statistically significant interaction was observed for elevated fasting glucose or elevated OGTT-2 h glucose. Similar but weaker results were observed for fatal and non-fatal CVD events separately (Additional file 1: Table S1).

Compared with participants without diabetes, participants with diabetes who had each individual controlled risk factor showed relatively lower hazards of CVD events among never smokers than among current or former smokers (Fig. 2A). Compared with participants without diabetes, participants with diabetes who had 5 or more controlled risk factors exhibited no significantly excess risk for CVD events (HR, 1.02; 95\% CI, 0.81-1.27; Table 4). Such favorable effect of 5 or more controlled risk factors on CVD risk was more prominent among never smokers (HR, 0.93; 95\% CI, 0.71-1.22), but was offset among current smokers (HR, 1.28; 95\% CI, 0.77-2.14) or former smokers (HR, 1.22; 95\% CI, 0.66-2.28; Fig. 2B).

\section{Discussion}

In this nationwide prospective cohort study in China, we have provided novel and quantitative data about the interplay of cigarette smoking with diabetes and cardiovascular risk factor management on subsequent risk of CVD events. Compared with adults without diabetes, adults with diabetes were more susceptible to the 

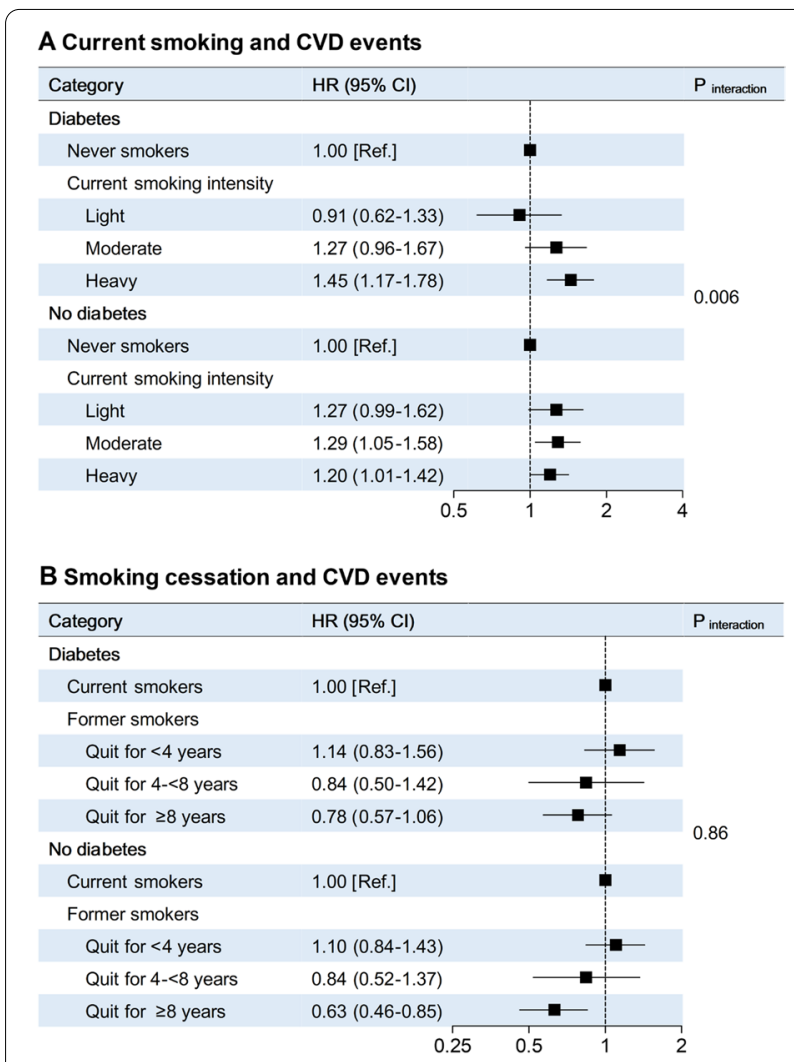

Fig. 1 Association of current smoking and smoking cessation with CVD events among participants with and without diabetes. A. Number of participants included in the analysis: 19,397 current smokers and 100,735 never smokers. Light smokers $(n=3020)$ referred to participants who smoked $<10$ cigarettes per day, moderate smokers $(n=5051)$ referred to participants who smoked $10-<20$ cigarettes per day, and heavy smokers $(n=11,326)$ referred to participants who smoked $\geq 20$ cigarettes per day. HRs (95\% Cls) and P value were adjusted for age, sex, education attainment (less than high school, high school or further education), family history of diabetes (yes, no), family history of CVD (yes, no), fruits and vegetables intake ( $<4.5$ cup/day, $\geq 4.5$ cup/day), physical activity (active, insufficiently active, inactive), alcohol consumption, hypertension (yes, no), dyslipidemia (yes, no), baseline BMI, BMI change during follow-up, and passive smoking exposure in childhood and adulthood. B. Number of participants included in the analysis: 6,049 former smokers and 19,397 current smokers. HRs (95\% Cls) and P value were adjusted for the same set of variables as shown in Panel $A$.

deleterious effect of current smoking, especially heavy smoking, on CVD events. From another perspective, the excess CVD risks associated with diabetes and elevated glycemic traits were exacerbated among current smokers and former smokers, and the beneficial effect of risk factor management on CVD events among adults with diabetes seemed to be substantially attenuated by current or former smoking.
Our findings support a bidirectional interaction between smoking and diabetes on incident CVD events. Cigarette smoking and diabetes contribute independently to increased risk of CVD [4-8], and among people with diabetes, smoking is the key lifestyle risk factor for CVD [6]. In addition, current smokers have longer duration of exposure to passive smoking than never smokers and passive smoking is associated with an increased risk of CVD [30-32]. Given the considerable prevalence of smoking and the relatively low smoking cessation rate among people with diabetes and the effects of passive smoking on aspects of human health $[14,15]$, the specific effect that smoking poses to the diabetes population deserves special attention, and exposure to secondhand smoke should be minimized or avoided in order to reduce public health hazards $[6,33]$. Prospective studies investigating the interaction between smoking and diabetes on CVD events are scarce and have revealed no evidence that the smoking-related CVD risk is greater in people with diabetes than in those without diabetes [34, 35]. In this study, taking advantage of a large nationwide sample with detailed records of smoking behaviors and comprehensive glycemic measurements, we extended previous evidence by showing that smoking and diabetes could amplify the deleterious effect of each other on subsequent risk of CVD, and the interaction between smoking and diabetes was quite consistent when diagnosing diabetes by each of the glycemic traits, especially elevated HbA1c. Our findings thus underline the importance of avoiding or quitting smoking for the effective prevention of CVD events, particularly for people with diabetes.

Our results also support a noteworthy conclusion that the favorable effects of optimal management of cardiovascular risk factors on incident CVD events among adults with diabetes could be considerably counteracted by smoking. Previous studies have demonstrated that substantial additional reductions in major CVD events in adults with diabetes can be achieved through ideal control of cardiovascular risk factors [16, 36-38]. In this study, the favorable cardiovascular effect of an ideal control of 5 or more risk factors in diabetes was only seen in never smokers; the CVD risk remained high among adults with diabetes who were current smokers or former smokers, even with optimal risk factor management. These results suggest that smoking is an important barrier for people with diabetes to gain cardiovascular benefits through risk factor management.

The precise mechanisms to explain our observations are unclear. Theoretically, both smoking and diabetes contribute to the development of cardiac dysfunction via promoting oxidative stress, inducing endothelial injury, 
Table 3 Association of diabetes, elevated fasting glucose, elevated OGTT-2 h glucose, and elevated HbA1c with CVD events among current, former, and never smokers

\begin{tabular}{|c|c|c|c|c|c|c|c|}
\hline \multirow[t]{2}{*}{ Category } & \multirow{2}{*}{$\begin{array}{l}\text { No. of } \\
\text { participants }\end{array}$} & \multirow[t]{2}{*}{ Person-years } & \multirow[t]{2}{*}{ Cases } & \multicolumn{3}{|l|}{ HR $(95 \% \mathrm{Cl})$} & \multirow[t]{2}{*}{$P$ for interaction ${ }^{c}$} \\
\hline & & & & $\begin{array}{l}\text { Adjusted } \\
\text { for CVD risk } \\
\text { factors }^{\mathrm{a}}\end{array}$ & $\begin{array}{l}\text { Further adjusted for } \\
\text { baseline BMI, and BMI } \\
\text { change }\end{array}$ & $\begin{array}{l}\text { Further adjusted } \\
\text { for passive } \\
\text { smoking }^{b}\end{array}$ & \\
\hline Diabetes & & & & & & & 0.034 \\
\hline \multicolumn{8}{|l|}{ Current smokers } \\
\hline No diabetes & 14,874 & 54,483 & 402 & 1.00 [Ref.] & 1.00 [Ref.] & 1.00 [Ref.] & \\
\hline Diabetes & 4523 & 16,226 & 233 & $1.60(1.35-1.89)$ & $1.61(1.36-1.91)$ & $1.61(1.36-1.91)$ & \\
\hline \multicolumn{8}{|l|}{ Former smokers } \\
\hline No diabetes & 4136 & 15,002 & 128 & 1.00 [Ref.] & 1.00 [Ref.] & 1.00 [Ref.] & \\
\hline Diabetes & 1913 & 6889 & 112 & $1.67(1.28-2.16)$ & $1.71(1.31-2.22)$ & $1.70(1.31-2.22)$ & \\
\hline \multicolumn{8}{|l|}{ Never smokers } \\
\hline No diabetes & 77,971 & 281,612 & 1604 & 1.00 [Ref.] & 1.00 [Ref.] & 1.00 [Ref.] & \\
\hline Diabetes & 22,764 & 81,515 & 943 & $1.38(1.27-1.50)$ & $1.37(1.26-1.49)$ & $1.37(1.26-1.49)$ & \\
\hline Elevated fasting glucose & & & & & & & 0.11 \\
\hline \multicolumn{8}{|l|}{ Current smokers } \\
\hline $\begin{array}{l}\text { Fasting glu- } \\
\text { cose }<126 \mathrm{mg} / \mathrm{dL}\end{array}$ & 16,722 & 61,110 & 484 & 1.00 [Ref.] & 1.00 [Ref.] & 1.00 [Ref.] & \\
\hline $\begin{array}{l}\text { Fasting glu- } \\
\text { cose } \geq 126 \mathrm{mg} / \mathrm{dL}\end{array}$ & 2653 & 9522 & 147 & $1.69(1.40-2.05)$ & $1.71(1.41-2.07)$ & $1.71(1.41-2.07)$ & \\
\hline \multicolumn{8}{|l|}{ Former smokers } \\
\hline $\begin{array}{l}\text { Fasting glu- } \\
\text { cose }<126 \mathrm{mg} / \mathrm{dL}\end{array}$ & 4931 & 17,868 & 172 & 1.00 [Ref.] & 1.00 [Ref.] & 1.00 [Ref.] & \\
\hline $\begin{array}{l}\text { Fasting glu- } \\
\text { cose } \geq 126 \mathrm{mg} / \mathrm{dL}\end{array}$ & 1110 & 3997 & 68 & $1.61(1.21-2.15)$ & $1.66(1.24-2.22)$ & $1.66(1.24-2.22)$ & \\
\hline \multicolumn{8}{|l|}{ Never smokers } \\
\hline $\begin{array}{l}\text { Fasting glu- } \\
\text { cose }<126 \mathrm{mg} / \mathrm{dL}\end{array}$ & 89,021 & 321,598 & 2011 & 1.00 [Ref.] & 1.00 [Ref.] & 1.00 [Ref.] & \\
\hline $\begin{array}{l}\text { Fasting glu- } \\
\text { cose } \geq 126 \mathrm{mg} / \mathrm{dL}\end{array}$ & 11,624 & 41,208 & 532 & $1.47(1.34-1.63)$ & $1.46(1.33-1.61)$ & $1.46(1.33-1.61)$ & \\
\hline $\begin{array}{l}\text { Elevated OGTT-2 } \mathrm{h} \\
\text { glucose }\end{array}$ & & & & & & & 0.28 \\
\hline \multicolumn{8}{|l|}{ Current smokers } \\
\hline $\begin{array}{l}\text { OGTT-2 h glu- } \\
\text { cose }<200 \mathrm{mg} / \mathrm{dL}\end{array}$ & 16,273 & 59,462 & 464 & 1.00 [Ref.] & 1.00 [Ref.] & 1.00 [Ref.] & \\
\hline $\begin{array}{l}\text { OGTT-2 h glu- } \\
\text { cose } \geq 200 \mathrm{mg} / \mathrm{dL}\end{array}$ & 3035 & 10,918 & 163 & $1.56(1.30-1.88)$ & $1.57(1.31-1.90)$ & $1.57(1.31-1.90)$ & \\
\hline \multicolumn{8}{|l|}{ Former smokers } \\
\hline $\begin{array}{l}\text { OGTT-2 h glu- } \\
\text { cose }<200 \mathrm{mg} / \mathrm{dL}\end{array}$ & 4697 & 16,999 & 160 & 1.00 [Ref.] & 1.00 [Ref.] & 1.00 [Ref.] & \\
\hline $\begin{array}{l}\text { OGTT-2 h glu- } \\
\text { cose } \geq 200 \mathrm{mg} / \mathrm{dL}\end{array}$ & 1282 & 4646 & 75 & $1.44(1.09-1.91)$ & $1.45(1.10-1.93)$ & $1.45(1.10-1.93)$ & \\
\hline \multicolumn{8}{|l|}{ Never smokers } \\
\hline $\begin{array}{l}\text { OGTT-2 h glu- } \\
\text { cose }<200 \text { mg/dL }\end{array}$ & 85,342 & 307,942 & 1844 & 1.00 [Ref.] & 1.00 [Ref.] & 1.00 [Ref.] & \\
\hline $\begin{array}{l}\text { OGTT-2 } \mathrm{h} \text { glu- } \\
\text { cose } \geq 200 \mathrm{mg} / \mathrm{dL}\end{array}$ & 14,869 & 53,371 & 684 & $1.44(1.32-1.58)$ & $1.43(1.31-1.57)$ & $1.44(1.31-1.58)$ & \\
\hline Elevated $\mathrm{HbA1c}$ & & & & & & & 0.011 \\
\hline
\end{tabular}


Table 3 (continued)

\begin{tabular}{|c|c|c|c|c|c|c|c|}
\hline \multirow[t]{2}{*}{ Category } & \multirow{2}{*}{$\begin{array}{l}\text { No. of } \\
\text { participants }\end{array}$} & \multirow[t]{2}{*}{ Person-years } & \multirow[t]{2}{*}{ Cases } & \multicolumn{3}{|l|}{$\mathrm{HR}(95 \% \mathrm{Cl})$} & \multirow[t]{2}{*}{$P$ for interaction ${ }^{c}$} \\
\hline & & & & $\begin{array}{l}\text { Adjusted } \\
\text { for CVD risk } \\
\text { factors }^{\mathrm{a}}\end{array}$ & $\begin{array}{l}\text { Further adjusted for } \\
\text { baseline BMI, and BMI } \\
\text { change }\end{array}$ & $\begin{array}{l}\text { Further adjusted } \\
\text { for passive } \\
\text { smoking }^{\text {b }}\end{array}$ & \\
\hline \multicolumn{8}{|l|}{ Current smokers } \\
\hline $\mathrm{HbA} 1 \mathrm{c}<6.5 \%$ & 16,402 & 59,910 & 467 & 1.00 [Ref.] & 1.00 [Ref.] & 1.00 [Ref.] & \\
\hline $\mathrm{HbA} 1 \mathrm{c} \geq 6.5 \%$ & 2955 & 10,652 & 167 & $1.69(1.41-2.04)$ & $1.72(1.42-2.07)$ & $1.72(1.43-2.07)$ & \\
\hline \multicolumn{8}{|l|}{ Former smokers } \\
\hline $\mathrm{HbA} 1 \mathrm{c}<6.5 \%$ & 4800 & 17,404 & 159 & 1.00 [Ref.] & 1.00 [Ref.] & 1.00 [Ref.] & \\
\hline $\mathrm{HbA} 1 \mathrm{c} \geq 6.5 \%$ & 1237 & 4446 & 78 & $1.77(1.34-2.34)$ & $1.83(1.38-2.43)$ & $1.83(1.38-2.43)$ & \\
\hline \multicolumn{8}{|l|}{ Never smokers } \\
\hline $\mathrm{HbA} 1 \mathrm{c}<6.5 \%$ & 85,759 & 309,451 & 1899 & 1.00 [Ref.] & 1.00 [Ref.] & 1.00 [Ref.] & \\
\hline $\mathrm{HbA} 1 \mathrm{c} \geq 6.5 \%$ & 14,849 & 53,219 & 643 & $1.39(1.27-1.52)$ & $1.38(1.25-1.51)$ & $1.37(1.25-1.51)$ & \\
\hline
\end{tabular}

126,181 participants were included in the analysis. The numbers of missing values are 120 for fasting glucose, 683 for OGTT-2 $\mathrm{h}$ glucose, and 179 for HbA1c

a Adjusted for age, sex, education attainment (less than high school, high school or further education), family history of diabetes (yes, no), family history of CVD (yes, no), fruits and vegetables intake ( $<4.5$ cup/day, $\geq 4.5$ cup/day), physical activity (active, insufficiently active, inactive), alcohol consumption, hypertension (yes, no), and dyslipidemia (yes, no)

${ }^{\mathrm{b}}$ Adjusted for CVD risk factors as listed above, as well as baseline BMI, BMI change during follow-up, and passive smoking exposure in childhood and adulthood ' Interactions of diabetes, elevated fasting glucose, elevated OGTT-2 $\mathrm{h}$ glucose, and elevated HbA1c with smoking status in relation to CVD events were adjusted for CVD risk factors as listed above, as well as baseline BMI, BMI change during follow-up, and passive smoking exposure in childhood and adulthood

Table 4 Association of cardiovascular risk factor management with CVD events among participants with diabetes, as compared with participants without diabetes

\begin{tabular}{|c|c|c|c|}
\hline Category & Person-years & Cases & $\mathrm{HR}(95 \% \mathrm{Cl})^{\mathrm{a}}$ \\
\hline No diabetes & 351,096 & 2134 & 1.00 [Ref.] \\
\hline \multicolumn{4}{|l|}{ Diabetes } \\
\hline \multicolumn{4}{|c|}{ Individual cardiovascular risk factor management } \\
\hline Optimal fruits and vegetables intake & 44,791 & 485 & $1.33(1.20-1.47)$ \\
\hline Optimal physical activity & 71,765 & 898 & $1.43(1.32-1.55)$ \\
\hline $\mathrm{HbA} 1 \mathrm{c}<6.5 \%$ & 35,669 & 391 & $1.27(1.14-1.42)$ \\
\hline $\mathrm{SBP} / \mathrm{DBP}<130 / 80 \mathrm{mmHg}$ & 29,104 & 221 & $1.12(0.97-1.28)$ \\
\hline LDL cholesterol $<100$ mg/dL & 37,126 & 397 & $1.28(1.15-1.43)$ \\
\hline No CKD & 100,376 & 1154 & $1.39(1.29-1.50)$ \\
\hline \multicolumn{4}{|c|}{ Overall cardiovascular risk factor management } \\
\hline 2 or fewer controlled risk factors & 34,699 & 542 & $1.79(1.62-1.97)$ \\
\hline 3 controlled risk factors & 34,582 & 428 & $1.50(1.35-1.67)$ \\
\hline 4 controlled risk factors & 24,629 & 238 & $1.25(1.09-1.43)$ \\
\hline 5 or more controlled risk factors & 10,720 & 80 & $1.02(0.81-1.27)$ \\
\hline
\end{tabular}

Number of participants included in the analysis of individual risk factor management: 96,981 without diabetes, 12,408 with diabetes and fruits and vegetables intake $>4.5$ cup/day, 19,921 with diabetes and physical activity $\geq 600 \mathrm{MET}$-min/week; 9,980 with diabetes and $\mathrm{HbA} 1 \mathrm{c}<6.5 \%$, 8,052 with diabetes and SBP/ $\mathrm{DBP}<130 / 80 \mathrm{mmHg}, 10,312$ with diabetes and LDL cholesterol $<100 \mathrm{mg} / \mathrm{dL}$, and 28,032 with diabetes and no CKD. Number of participants included in the analysis of overall risk factor management: 96,981 without diabetes, 9,753 with diabetes and $\leq 2$ controlled risk factors, 9,667 with diabetes and 3 controlled risk factors, 6,846 with diabetes and 4 controlled risk factors, and 2,934 with diabetes and $\geq 5$ controlled risk factors

${ }^{a}$ For analysis of individual risk factor management: adjusted for age, sex, education attainment (less than high school, high school or further education), family history of diabetes (yes, no), family history of CVD (yes, no), fruits and vegetables intake ( $<4.5$ cup/day, $\geq 4.5$ cup/day; not for fruits and vegetables intake analysis), physical activity (active, insufficiently active, inactive; not for physical activity analysis), alcohol consumption, hypertension (yes, no; not for SBP/DBP analysis), dyslipidemia (yes, no; not for LDL cholesterol analysis), baseline BMI, BMI change during follow-up, active smoking (never smoker, former smoker, current smoker), and passive smoking exposure in childhood and adulthood. For analysis of overall risk factor management: adjusted for age, sex, education attainment (less than high school, high school or further education), family history of diabetes (yes, no), family history of CVD (yes, no), alcohol consumption, baseline BMI, BMI change during follow-up, active smoking (never, former, current smoking), and passive smoking exposure in childhood and adulthood 


\begin{tabular}{|c|c|c|c|c|}
\hline \multicolumn{4}{|c|}{ A Individual risk factor management and CVD events } & \\
\hline \multirow{2}{*}{$\begin{array}{l}\text { Category } \\
\text { No diabetes }\end{array}$} & \multicolumn{2}{|l|}{$\mathrm{HR}(95 \% \mathrm{Cl})$} & & \\
\hline & 1.00 [Ref]] & 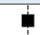 & & \\
\hline \multicolumn{5}{|l|}{ Diabetes } \\
\hline \multicolumn{5}{|c|}{ Optimal fruits and vegetables intake } \\
\hline Current smokers & $1.51(1.19-1.92)$ & & $\rightarrow-$ & \\
\hline Former smokers & $1.56(1.17-2.07)$ & & $\longrightarrow$ & \\
\hline Never smokers & $1.26(1.12-1.42)$ & & $=$ & \\
\hline \multicolumn{5}{|c|}{ Optimal physical activity } \\
\hline Current smokers & $1.91(1.61-2.25)$ & & $\rightarrow$ & \\
\hline Former smokers & $1.53(1.22-1.91)$ & & - & \\
\hline Never smokers & $1.33(1.21-1.45)$ & & $=$ & \\
\hline \multicolumn{5}{|l|}{$\mathrm{HbA} 1 \mathrm{C}<6.5 \%$} \\
\hline Current smokers & $1.49(1.16-1.92)$ & & $\rightarrow$ & \\
\hline Former smokers & $1.20(0.84-1.72)$ & & $=$ & \\
\hline Never smokers & $1.23(1.08-1.39)$ & & - & \\
\hline \multicolumn{5}{|c|}{$\mathrm{SBP} / \mathrm{DBP}<130 / 80 \mathrm{mmHg}$} \\
\hline Current smokers & $1.38(1.03-1.87)$ & & $\because-$ & \\
\hline Former smokers & $1.77(1.20-2.59)$ & & $\because$ & \\
\hline Never smokers & $0.99(0.84-1.18)$ & $\rightarrow$ & & \\
\hline \multicolumn{5}{|c|}{ LDL cholesterol $<100 \mathrm{mg} / \mathrm{dL}$} \\
\hline Current smokers & $1.69(1.34-2.13)$ & & $=$ & \\
\hline Former smokers & $1.37(0.99-1.87)$ & & $\because-$ & \\
\hline Never smokers & $1.17(1.03-1.33)$ & & - & \\
\hline \multicolumn{5}{|l|}{ No CKD } \\
\hline Current smokers & $1.82(1.57-2.11)$ & & $\rightarrow$ & \\
\hline Former smokers & $1.53(1.24-1.88)$ & & - & \\
\hline \multirow[t]{2}{*}{ Never smokers } & $1.29(1.19-1.40)$ & & $=$ & \\
\hline & 0.5 & 1 & 2 & 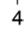 \\
\hline \multicolumn{5}{|c|}{ B Overall risk factor management and CVD events } \\
\hline Category & \multicolumn{3}{|l|}{$\mathrm{HR}(95 \% \mathrm{Cl})$} & \\
\hline No diabetes & 1.00 [Ref.] & $i$ & & \\
\hline \multicolumn{5}{|l|}{ Diabetes } \\
\hline \multicolumn{5}{|c|}{2 or fewer controlled risk factors } \\
\hline Current smokers & $2.33(1.88-2.86)$ & & $\rightarrow$ & \\
\hline Former smokers & $1.92(1.39-2.64)$ & & 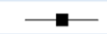 & \\
\hline Never smokers & $1.67(1.50-1.86)$ & & $\Rightarrow$ & \\
\hline \multicolumn{5}{|c|}{3 controlled risk factors } \\
\hline Current smokers & $1.99(1.59-2.50)$ & & $\rightarrow$ & \\
\hline Former smokers & $1.43(1.02-2.02)$ & & $=-$ & \\
\hline Never smokers & $1.41(1.25-1.59)$ & & + & \\
\hline \multicolumn{5}{|c|}{4 controlled risk factors } \\
\hline Current smokers & $1.37(0.99-1.89)$ & & $=$ & \\
\hline Former smokers & $1.57(1.09-2.28)$ & & 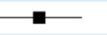 & \\
\hline Never smokers & $1.18(1.01-1.39)$ & & - & \\
\hline \multicolumn{5}{|c|}{5 or more controlled risk factors } \\
\hline Current smokers & $1.28(0.77-2.14)$ & & 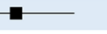 & \\
\hline Former smokers & $1.22(0.66-2.28)$ & & - & \\
\hline \multirow[t]{2}{*}{ Never smokers } & $0.93(0.71-1.22)$ & $\boldsymbol{E}$ & & \\
\hline & 0.5 & 1 & 2 & 4 \\
\hline
\end{tabular}

and leading formation of atheroma [39], and these shared pathogenic pathways may underlie the interplay between smoking and diabetes on CVD. In addition, smoking is independently associated with the devastating cardiovascular health consequences for people with diabetes [39, 40]. Therefore, the benefits of ideal management of other risk factors may not fully outweigh the smoking-related cardiovascular risk. Experimental studies are needed to shed light on potential mechanisms responsible for the interplay between smoking and diabetes on CVD risk.
Fig. 2 Association of cardiovascular risk factor management with CVD events among participants with diabetes according to smoking status, as compared with participants without diabetes. A. Number of participants included in the analysis: 96,981 without diabetes, 12,408 with diabetes and fruits and vegetables intake $\geq 4.5$ cup/ day, 19,921 with diabetes and physical activity $\geq 600$ MET-min/ week; 9980 with diabetes and $\mathrm{HbA1c}<6.5 \%, 8052$ with diabetes and SBP/DBP $<130 / 80 \mathrm{mmHg}, 10,312$ with diabetes and LDL cholesterol $<100 \mathrm{mg} / \mathrm{dL}$, and 28,032 with diabetes and no CKD. HRs ( $95 \% \mathrm{Cls}$ ) were adjusted for age, sex, education attainment (less than high school, high school or further education), family history of diabetes (yes, no), family history of CVD (yes, no), fruits and vegetables intake ( $<4.5$ cup/day, $\geq 4.5$ cup/day; not for fruits and vegetables intake analysis), physical activity (active, insufficiently active, inactive; not for physical activity analysis), alcohol consumption, hypertension (yes, no; not for SBP/DBP analysis), dyslipidemia (yes, no; not for LDL cholesterol analysis), baseline BMI, BMI change during follow-up, and passive smoking exposure in childhood and adulthood. B. Number of participants included in the analysis: 96,981 without diabetes, 9753 with diabetes and $\leq 2$ controlled risk factors, 9667 with diabetes and 3 controlled risk factors, 6,846 with diabetes and 4 controlled risk factors, and 2934 with diabetes and $\geq 5$ controlled risk factors. HRs (95\% Cls) were adjusted for age, sex, education attainment (less than high school, high school or further education), family history of diabetes (yes, no), family history of CVD (yes, no), alcohol consumption, baseline BMI, BMI change during follow-up, and passive smoking exposure in childhood and adulthood.

The strengths of this study included the large nationwide sample size, the prospective study design, the detailed records of smoking behaviors and comprehensive measurements of glycemic traits, and the wellvalidated definitions of the CVD outcomes. This study also has several limitations. First, the self-reported nature of smoking information may underestimate the prevalence of smoking as ascertained by cotinine measurement, and biochemical verification is needed to confirm the findings of this study. Second, we could not fully consider the residual and unmeasured confounders, such as the use of aspirin and metformin, which has been suggested to help prevent CVD risk in certain patients [41]. Third, the large sample size of this study can enhance the reliability of our findings and has advantages in permitting stratified analyses. However, because of the large sample size in this study, a statistically significant finding might not necessarily be clinically significant; thus, significant findings derived from this study must be analyzed and interpreted with caution. Fourth, similar to previous National Smoking Survey [42] and China Noncommunicable Disease Surveillance [43], the proportion of smokers were extremely low in Chinese women. Therefore, the limited number of smokers restricted the statistical power to perform sex-stratification analysis in this study. Fifth, the participants were middle-aged and elderly Chinese 
adults, and a majority of current smokers and former smokers were men. Thus, the generalizability of our findings to other groups should be cautious.

\section{Conclusions}

Smoking and diabetes significantly interacted with each other in imposing increased risks of subsequent CVD events, and the cardiovascular benefits of risk factor management in diabetes could be counteracted by former or current smoking. Our findings highlight the particular importance of avoiding or quitting smoking to reduce the preventable burden of CVD in people with diabetes.

\section{Abbreviations}

CKD: Chronic kidney disease; CVD: Cardiovascular disease; DBP: Diastolic blood pressure; eGFR: Estimated glomerular filtration rate; HbA1c: Hemoglobin A1c; HDL: High-density lipoprotein; LDL: Low-density lipoprotein; MET: Metabolic equivalent; OGTT: Oral glucose tolerance test; SBP: Systolic blood pressure.

\section{Supplementary Information}

The online version contains supplementary material available at https://doi. org/10.1186/s12933-022-01447-2.

Additional file 1: Table S1. Association of diabetes, elevated fasting glucose, elevated OGTT-2h glucose, and elevated $\mathrm{HbA1} \mathrm{c}$ with non-fatal CVD events and CVD mortality among current, former, and never smokers. 126,181 participants were included in the analysis. The numbers of missing values are 120 for fasting glucose, 683 for OGTT-2h glucose, and 179 for HbAlc. aAdjusted for age, sex, education attainment (less than high school, high school or further education), family history of diabetes (yes, no), family history of CVD (yes, no), fruits and vegetables intake ( $<4.5$ cup/ day, $\geq 4.5$ cup/day), physical activity (active, insufficiently active, inactive), alcohol consumption, hypertension (yes, no), dyslipidemia (yes, no), baseline BMI, BMI change during follow-up, and passive smoking exposure in childhood and adulthood. bPerson-years for CVD mortality was longer than that for non-fatal CVD events, because participants may have experienced more than one CVD event. Figure S1. Association of current smoking with non-fatal CVD events and CVD mortality among participants with and without diabetes. Number of participants included in the analysis: 19,397 current smokers and 100,735 never smokers. Light smokers $(n=3,020)$ referred to participants who smoked $<10$ cigarettes per day, moderate smokers $(n=5,051)$ referred to participants who smoked $10-<20$ cigarettes per day, and heavy smokers $(n=11,326)$ referred to participants who smoked $\geq 20$ cigarettes per day. HRs $(95 \% \mathrm{Cls})$ and $\mathrm{P}$ value were adjusted for age, sex, education attainment (less than high school, high school or further education), family history of diabetes (yes, no), family history of CVD (yes, no), fruits and vegetables intake ( $<4.5$ cup/day, $\geq 4.5$ cup/day), physical activity (active, insufficiently active, inactive), alcohol consumption, hypertension (yes, no), dyslipidemia (yes, no), baseline BMI, $\mathrm{BMI}$ change during follow-up, and passive smoking exposure in childhood and adulthood. Figure S2. Association of smoking cessation with nonfatal CVD events and CVD mortality among participants with and without diabetes. Number of participants included in the analysis: 6,049 former smokers and 19,397 current smokers. HRs (95\% Cls) and P value were adjusted for age, sex, education attainment (less than high school, high school or further education), family history of diabetes (yes, no), family history of CVD (yes, no), fruits and vegetables intake ( $<4.5$ cup/day, $\geq 4.5$ cup/day), physical activity (active, insufficiently active, inactive), alcohol consumption, hypertension (yes, no), dyslipidemia (yes, no), baseline BMI, $\mathrm{BMI}$ change during follow-up, and passive smoking exposure in childhood and adulthood.

\section{Acknowledgements}

The authors thank all the study participants and research staff involved in the China Cardiometabolic Disease and Cancer Cohort Study and the members of the endocrinology department to Ruijin hospital for their support.

\section{Authors' contributions}

YY, NP, QZ, and LS conceived and designed the study. All authors contributed to the acquisition or interpretation of the data. YY drafted the manuscript. NP conducted the analyses. YY, NP, and TW contributed to the statistical analysis. All authors contributed to the interpretation of the results and critical revision of the manuscript for important intellectual content. QZ, LS, WW, and GN contributed to funding acquisition. QZ and LS contributed to supervision and had full access to all of the data in the study and take responsibility for the integrity of the data and the accuracy of the data analysis. All authors approved the final version of the manuscript.

\section{Funding}

The 4C study was funded by Shanghai Key Laboratory for Endocrine Tumors, National Key R\&D Program of China (2016YFC1305600, 2016YFC1305202, 2016YFC1304904, 2017YFC1310700, 2017YFC1309804, 2017YFC1309805, 2018YFC1311705, and 2018YF(1311800). This work was also funded by the Special Precision Medicine Project of the National Key R\&D Program from the Science and Technology Ministry China(2016YFC0901203), Special Scientific Research Fund of Public Welfare Profession from the National Health and Family Planning Commission of PRC (201502007), and Key Clinical Specialty Cultivation Project of Guizhou Province (SZD-2016-01).

\section{Availability of data and materials}

The datasets used and analyzed during the current study are available from the corresponding author on reasonable request.

\section{Declarations}

Ethical approval and consent to participate

This study was approved by the Medical Ethics Committee of Ruijin Hospital, Shanghai Jiao Tong University. All study participants provided written informed consent.

\section{Consent for publication}

Not applicable.

\section{Competing interests}

The authors declare that they have no competing interests.

\section{Author details}

${ }^{1}$ Department of Endocrinology and Metabolism, Affiliated Hospital of Guizhou Medical University, Guizhou Medical University, Guiyang, China. ${ }^{2}$ Fujian Provincial Hospital, Fujian Medical University, Fuzhou, China. ${ }^{3}$ The Affiliated Hospital of Luzhou Medical College, Luzhou, China. ${ }^{4}$ Sun Yat-Sen Memorial Hospital, Sun Yat-Sen University, Guangzhou, China. ${ }^{5}$ The First Hospital of Jilin University, Changchun, China. ${ }^{6}$ The First Affiliated Hospital of Guangxi Medical University, Nanning, China. ${ }^{7}$ The First Hospital of Lanzhou University, Lanzhou, China. ${ }^{8}$ Jiangxi Provincial People's Hospital Affiliated To Nanchang University, Nanchang, China. ${ }^{9}$ Zhejiang Provincial Center for Disease Control and Prevention, Hangzhou, China. ${ }^{10}$ Division of Endocrinology, Department of Internal Medicine, The First Affiliated Hospital of Zhengzhou University, Zhengzhou, China. ${ }^{11}$ Dalian Municipal Central Hospital, Dalian, China. ${ }^{12}$ Xinhua Hospital Affiliated to Shanghai Jiaotong University School of Medicine, Shanghai, China. ${ }^{13}$ Chinese People's Liberation Army General Hospital, Beijing, China.

${ }^{14}$ Shandong Provincial Hospital Affiliated To Shandong University, Jinan, China.

${ }^{15}$ Union Hospital, Tongji Medical College, Huazhong University of Science and Technology, Wuhan, China. ${ }^{16}$ Tongji Hospital, Tongji Medical College, Huazhong University of Science and Technology, Wuhan, China. ${ }^{17}$ The Second Affiliated Hospital of Harbin Medical University, Harbin, China. ${ }^{18}$ The First Affiliated Hospital of Wenzhou Medical University, Wenzhou, China. ${ }^{19}$ Qilu Hospital of Shandong University, Jinan, China. ${ }^{20}$ Central Hospital of Shanghai Jiading District, Shanghai, China. ${ }^{21}$ The First Affiliated Hospital of Anhui 
Medical University, Hefei, China. ${ }^{22}$ The First Affiliated Hospital of Chongqing Medical University, Chongqing, China. ${ }^{23}$ Jiangsu Province Hospital On Integration of Chinese and Western Medicine, Nanjing, China. ${ }^{24}$ Karamay Municipal People's Hospital, Xinjiang, China. ${ }^{25}$ The First Affiliated Hospital of Nanjing Medical University, Nanjing, China. ${ }^{26}$ Department of Endocrine and Metabolic Diseases, Shanghai Institute of Endocrine and Metabolic Diseases, Ruijin Hospital, Shanghai Jiao Tong University School of Medicine, Shanghai, China. ${ }^{27}$ Shanghai National Clinical Research Center for Metabolic Diseases, Key Laboratory for Endocrine and Metabolic Diseases of the National Health Commission of the PR China, Shanghai National Center for Translational Medicine, Ruijin Hospital, Shanghai Jiao Tong University School of Medicine, Shanghai, China. ${ }^{28}$ Department of Endocrinology and Metabolism, GuiQian International General Hospital, Guiyang, China.

Received: 14 October 2021 Accepted: 8 January 2022 Published online: 24 January 2022

\section{References}

1. GBD 2015 Tobacco Collaborators. Tobacco Collaborators (2017) Smoking prevalence and attributable disease burden in 195 countries and territories, 1990-2015: a systematic analysis from the Global Burden of Disease Study 2015. Lancet. 2017;389(10082):1885-906.

2. Barua RS, Rigotti NA, Benowitz NL, Cummings KM, Jazayeri MA, Morris PB, et al. 2018 ACC expert consensus decision pathway on tobacco cessation treatment: a report of the american college of cardiology task force on clinical expert consensus documents. J Am Coll Cardiol. 2018;72(25):3332-65.

3. Zhou M, Wang H, Zeng X, Yin P, Zhu J, Chen W, et al. Mortality, morbidity, and risk factors in China and its provinces, 1990-2017: a systematic analysis for the Global Burden of Disease Study 2017. Lancet. 2019;394(10204):1145-58.

4. Hackshaw A, Morris JK, Boniface S, Tang JL, Milenković D. Low cigarette consumption and risk of coronary heart disease and stroke: meta-analysis of 141 cohort studies in 55 study reports. BMJ. 2018;360:5855

5. Duncan MS, Freiberg MS, Greevy RA Jr, Kundu S, Vasan RS, Tindle HA. Association of smoking cessation with subsequent risk of cardiovascular disease. JAMA. 2019;322(7):642-50.

6. Pan A, Wang Y, Talaei M, Hu FB. Relation of smoking with total mortality and cardiovascular events among patients with diabetes mellitus: a meta-analysis and systematic review. Circulation. 2015;132(19):1795-804.

7. Emerging Risk Factors Collaboration1, Sarwar N, Gao P, Kondapally Seshasai SR, Gobin R, Kaptoge S, Di Angelantonio E, et al. Diabetes mellitus, fasting blood glucose concentration, and risk of vascular disease: a collaborative meta-analysis of 102 prospective studies. Lancet. 2010;375(9733):2215-22.

8. Rao Kondapally Seshasai S, Kaptoge S, Thompson A, Di Angelantonio E, Sarwar N, Peter H, et al. Diabetes mellitus, fasting glucose, and risk of cause-specific death. N Engl J Med. 2011;364(9):829-41.

9. Zheng Y, Ley SH, Hu FB. Global aetiology and epidemiology of type 2 diabetes mellitus and its complications. Nat Rev Endocrinol. 2018;14(2):88-98.

10. Newman JD, Schwartzbard AZ, Weintraub HS, Goldberg IJ, Berger JS. Primary prevention of cardiovascular disease in diabetes mellitus. J Am Coll Cardiol. 2017;70(7):883-93.

11. American Diabetes Association. 5. Lifestyle management: standards of medical care in diabetes-2019. Diabetes Care. 2019;42(Suppl1):S46-60.

12. American Diabetes Association. 10. Cardiovascular disease and risk management: standards of medical care in diabetes-2019. Diabetes Care. 2019:42(Suppl 1):S103-23.

13. Lightwood JM, Glantz SA. Short-term economic and health benefits of smoking cessation: myocardial infarction and stroke. Circulation. 1997;96(4):1089-96.

14. Cho MH, Kim SM, Lee K, Park SM, Chang J, Choi S, et al. Factors associated with continued smoking after the diagnosis of type 2 diabetes: a retrospective study in the Korean cohort. BMJ Open. 2018;8(6):e020160.

15. Tonstad S. Cigarette smoking, smoking cessation, and diabetes. Diabetes Res Clin Pract. 2009;85(1):4-13.
16. Wang T, Lu J, Su Q, Chen Y, Bi Y, Mu Y, et al. Ideal cardiovascular health metrics and major cardiovascular events in patients with prediabetes and diabetes. JAMA Cardiol. 2019;4(9):874-83.

17. Wang T, Lu J, Shi L, Chen G, Xu M, XuY Y, et al. Association of insulin resistance and $\beta$-cell dysfunction with incident diabetes among adults in China: a nationwide, population-based, prospective cohort study. Lancet Diabetes Endocrinol. 2020;8(2):115-24.

18. Craig CL, Marshall AL, Sjöström M, Bauman AE, Booth ML, Ainsworth $B E$, et al. International physical activity questionnaire: 12-country reliability and validity. Med Sci Sports Exerc. 2003;35(8):1381-95.

19. Ainsworth BE, Haskell WL, Leon AS, Jacobs DR, Montoye HJ, Sallis JF, et al. Compendium of physical activities: classification of energy costs of human physical activities. Med Sci Sports Exerc. 1993;25(1):71-80.

20. Expert Panel on Detection, Evaluation, and Treatment of High Blood Cholesterol in Adults. Executive summary of the third report of the national cholesterol education program (NCEP) expert panel on detection, evaluation, and treatment of high blood cholesterol in adults (Adult Treatment Panel III). JAMA. 2001;285(19):2486-97.

21. Levey AS, Stevens LA, Schmid CH, Zhang Y, Castro AF III, Feldman HI, et al. A new equation to estimate glomerular filtration rate. Ann Intern Med. 2009;150(9):604-12

22. Song $\mathrm{YM}, \mathrm{Cho} \mathrm{HJ}$. Risk of stroke and myocardial infarction after reduction or cessation of cigarette smoking: a cohort study in korean men. Stroke. 2008;39(9):2432-8.

23. American Diabetes Association. Diagnosis and classification of diabetes mellitus. Diabetes Care. 2010;33(Suppl 1):S62-9.

24. Lloyd-Jones DM, Hong Y, Labarthe D, Mozaffarian D, Appel LJ, Horn LV, et al; American Heart Association Strategic Planning Task Force and Statistics Committee. Defining and setting national goals for cardiovascular health promotion and disease reduction: the American Heart Association's strategic Impact Goal through 2020 and beyond. Circulation. 2010;121(4):586-613.

25. Lear SA, Hu W, Rangarajan S, Gasevic D, Leong D, labal R, et al. The effect of physical activity on mortality and cardiovascular disease in 130000 people from 17 high-income, middle-income, and low-income countries: the PURE study. Lancet. 2017;390(10113):2643-54.

26. American Diabetes Association. 6. Glycemic targets: standards of medical care in diabetes-2018. Diabetes Care. 2018:41(suppl1):S55-64.

27. Tian J, Sheng C, Sun W, Song X, Wang H, Li Q, et al. Effects of high blood pressure on cardiovascular disease events among chinese adults with different glucose metabolism. Diabetes Care. 2018;41 (9):1895-900.

28. Whelton PK, Carey RM, Aronow WS, Casey DE, Collins KJ, Himmelfarb CD, et al. 2017 ACC/AHA/AAPA/ABC/ACPM/AGS/APhA/ASH/ASPC/NMA/ PCNA guideline for the prevention, detection, evaluation, and management of high blood pressure in adults: executive summary: a report of the American College of Cardiology/American Heart Association Task Force on Clinical Practice Guidelines. Circulation. 2018;138(10):e426-83.

29. American Diabetes Association. 10. Cardiovascular disease and risk management: standards of medical care in diabetes-2021. Diabetes Care. 2021;44(Suppl 1):S125-50.

30. He J, Vupputuri S, Allen K, Prerost MR, Hughes J, Whelton PK. Passive smoking and the risk of coronary heart disease - a meta-analysis of epidemiologic studies. N Engl J Med. 1999;340(12):920-6.

31. Eze IC, Schaffner E, Zemp E, Eckardstein A, Turk A, Bettschart R, et al. Environmental tobacco smoke exposure and diabetes in adult neversmokers. Environ Health. 2014;13(1):74-82.

32. Khoramdad M, Vahedian-Azimi A, Karimi L, Rahimi-Bashar F, Amini $\mathrm{H}$, Sahebkar A. Association between passive smoking and cardiovascular disease: a systematic review and meta-analysis. IUBMB Life. 2020;72(11):677-86.

33. Connor Gorber S, Schofield-Hurwitz S, Hardt J, Levasseur G, Tremblay M. The accuracy of self-reported smoking: a systematic review of the relationship between self-reported and cotinine-assessed smoking status. Nicotine Tob Res. 2009;11(1):12-24.

34. Al-Delaimy WK, Manson JE, Solomon CG, Kawachi I, Stampfer MJ, Willett WC, Hu FB. Smoking and risk of coronary heart disease among women with type 2 diabetes mellitus. Arch Intern Med. 2002;162(3):273-9.

35. Fagard RH. Smoking amplifies cardiovascular risk in patients with hypertension and diabetes. Diabetes Care. 2009;32(Suppl 2):S429-31. 
36. Vazquez-Benitez G, Desai JR, Xu S, Goodrich GK, Schroeder EB, Nichols GA, et al. Preventable major cardiovascular events associated with uncontrolled glucose, blood pressure, and lipids and active smoking in adults with diabetes with and without cardiovascular disease: a contemporary analysis. Diabetes Care. 2015;38(5):905-12.

37. Liu G, Li Y, Hu Y, Zong G, Li S, Rimm EB, et al. Influence of lifestyle on incident cardiovascular disease and mortality in patients with diabetes mellitus. J Am Coll Cardiol. 2018;71(25):2867-76.

38. Rawshani A, Rawshani A, Franzén S, Sattar N, Eliasson B, Svensson A, et al. Risk factors, mortality, and cardiovascular outcomes in patients with type 2 diabetes. N Engl J Med. 2018;379(7):633-44

39. Niemann B, Rohrbach S, Miller MR, Newby DE, Fuster V, Kovacic JC. Oxidative stress and cardiovascular risk: obesity, diabetes, smoking, and pollution: part 3 of a 3-part series. J Am Coll Cardiol. 2017;70(7):230-51.

40. Rigotti NA, Clair C. Managing tobacco use: the neglected cardiovascular disease risk factor. Eur Heart J. 2013;34(42):3259-67.

41. Arnett DK, Blumenthal RS, Albert MA, Buroker AB, Goldberger ZD, Hahn EJ, et al. 2019 ACC/AHA guideline on the primary prevention of cardiovascular disease. Circulation. 2019;140(11):e596-646.

42. Liu S, Zhang M, Yang L, Li Y, Wang L, Huang Z, et al. Prevalence and patterns of tobacco smoking among Chinese adult men and women: findings of the 2010 national smoking survey. J Epidemiol Community Health. 2017;71(2):154-61.

43. Xu Y, Wang L, He J, et al; 2010 China Noncommunicable Disease Surveillance Group. Prevalence and control of diabetes in Chinese adults. JAMA. 2013;310(9):948-59.

\section{Publisher's Note}

Springer Nature remains neutral with regard to jurisdictional claims in published maps and institutional affiliations.

- fast, convenient online submission

- thorough peer review by experienced researchers in your field

- rapid publication on acceptance

- support for research data, including large and complex data types

- gold Open Access which fosters wider collaboration and increased citations

- maximum visibility for your research: over 100M website views per year

At BMC, research is always in progress.

Learn more biomedcentral.com/submissions 